\title{
Synthesis of Very Small Polymer Particles by Catalytic Polymerization in Aqueous Systems
}

\author{
Stefan Mecking, * Vincent Monteil, Johannes Huber, Ludmila Kolb, Peter Wehrmann
}

Summary: The preparation of aqueous dispersions of very small particles (size $<30$ $\mathrm{nm}$ ) of various polymers (polyethylenes, stereoregular 1,2-polybutadiene, and polyalkenamers) by catalytic polymerization with a water-soluble catalyst, or with microemulsions of lipophilic catalysts is reviewed.

Keywords: catalytic polymerization; latices; microemulsions; polymer dispersions; polyolefins

\section{Introduction and Background}

In general terms, submicron particles can be prepared either by disintegration of larger entities, or by synthesis from small building blocks such as atoms, ions or molecules. By comparison to disintegration techniques, the latter approach provides efficient access to particles down to the nanometer size regime; and it can allow for the controlled synthesis of particles in terms of size, size distribution and morphology. Examples are the synthesis of noble metal colloids by reduction of solutions of metal ions, or the synthesis of polymer dispersions by emulsion polymerization.

Classical emulsion polymerization provides particles with sizes in the range of ca. $1 \mu \mathrm{m}$ down to $50 \mathrm{~nm}$. Smaller particles are accessible in some cases by microemulsion polymerization as a special technique, as outlined below. ${ }^{[1,2]}$

By comparison to these well established free-radical polymerizations, catalytic synthesis of polymer dispersions offers a number of unique features. ${ }^{[3-17]}$ Polymer microstructures, and thus morphologies of particles, and of materials prepared thereof, can be controlled by the catalyst. Catalytic polymerization is complementary to radical

Universität Konstanz, Fachbereich Chemie, Universitätsstr. 10, 78464 Konstanz, Germany

Fax: +49 7531 88-5152

E-mail: stefan.mecking@uni-konstanz.de polymerization to a large extent in terms of the monomers suited, and correspondingly the polymers accessible.

In the past few years, we and the group of Spitz and Claverie have studied the synthesis of polyethylene dispersions by catalytic polymerization in some detail.

\section{Catalyst Types for Ethylene Polymerization in Aqueous Emulsion}

Two types of catalyst system have emerged for ethylene polymerization in aqueous systems, nickel(II)phosphinoenolate complexes $^{[10-15]}$ (1) and nickel(II) salicylaldiminato complexes ${ }^{[12,16,17]}(\mathbf{2})$. Both types of catalysts had originally been developed for non-aqueous polymerizations. ${ }^{[18-23]}$

The former (type 1) generally produce low molecular weight linear polyethylene $\left(\mathrm{M}_{\mathrm{n}}<10^{4} \mathrm{~g} \mathrm{~mol}^{-1}\right)$. Latex synthesis with a catalytic activity of up to $1.7 \times 10^{5} \mathrm{TO} \mathrm{h}^{-1}$ has been published to date $(\mathrm{TO}=$ turnovers, mol ethylene converted per mol Ni). ${ }^{[13]}$ Crystallinity can be reduced by copolymerization, albeit at a further expense of molecular weight and also reduced catalyst activities by comparison to ethylene homopolymerization. ${ }^{[14,15]}$ Polymerization with well-defined complexes as a catalyst precursor as well as with in situ prepared catalysts has been studied. The latter in situ catalysts can be prepared entirely from commercially available components, ${ }^{[15]}$ in addition the catalyst is also quite robust 


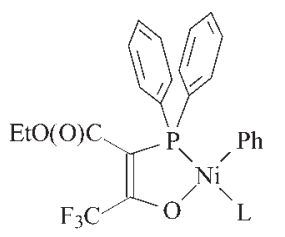

example of a

Ni-phosphinoenolate complex, 1

in terms of handling and stability under polymerization conditions.

By comparison, salicylaldiminato complexes are more versatile catalyst precursors in terms of polymer microstructures accessible. The modular synthesis of the ligands also makes these catalysts amenable for systematic structural variations. Latices of high molecular weight polyethylene $\left(M_{n}>\right.$ $10^{5} \mathrm{~g} \mathrm{~mol}^{-1}$ ) can be prepared. ${ }^{[16]}$ In ethylene homopolymerization, branching and thus crystallinity can be varied over a wide range from linear semicrystalline to highly branched entirely amorphous by the substitution pattern of the salicylaldiminato ligand (albeit an increase in branching is accompanied by a reduction in molecular weight, both effects being related to an increased $\mathrm{B}$ hydride transfer). ${ }^{[17]}$ Copolymerization is an alternative for crystallinity control independent of molecular weight. ${ }^{[12,24]}$

Both types of catalyst can be active in aqueous emulsion polymerization for hours.

\section{Polymerization with Catalyst Miniemulsions}

A general prerequisite for the preparation of colloidally stable polymer dispersions is a high degree of dispersion of the catalyst precursor in the initial reaction mixture. If this is not the case the polymer will be obtained in the form of large particles which separate from the reaction mixture, akin to a suspension polymerization. ${ }^{[25]}$ The route utilized most often in literature reports on ethylene polymerization to date is a miniemulsion technique, employing a lipophilic catalyst precursor. A solution of a lipophilic catalyst in a small amount of

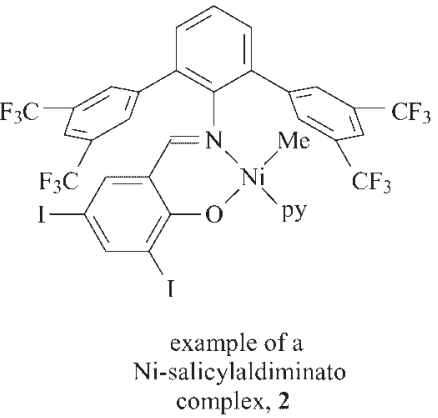

organic solvent (e.g. toluene) containing a hydrophobe (e.g. hexadecane), is mixed with an aqueous surfactant solution and miniemulsified by means of high shear, generated by ultrasound. Shearing results in the formation of small droplets, which are stabilized towards Ostwald ripening by the osmotic pressure exerted by the hydrophobe. ${ }^{[26]}$ The resulting 'catalyst miniemulsion' is transferred to a pressure reactor and exposed to ethylene under stirring (Scheme 1), affording a polyethylene dispersion.

This procedure differs from typical freeradical miniemulsion polymerization, which involves miniemulsification of the monomer (liquid under reaction conditions) and subsequent polymerization in the monomer droplets, the resulting polymer particles ideally being a 1:1 replica of the droplets. ${ }^{[27-29]}$ It can be noted that analogous catalytic polymerizations of monomer miniemulsions have been reported recently. Norbornene was polymerized via a ROMP or an insertion mechanism, respectively, to afford polymer latices. ${ }^{[30,31]}$

Regarding polymer particle formation in the ethylene polymerization with a catalyst miniemulsion, it can be assumed that in the case of semicrystalline polymer the latter precipitates in the miniemulsion droplets rapidly, forming new particles. Average particle sizes in the range of $70 \mathrm{~nm}$ to $1 \mu \mathrm{m}$ have been reported, ${ }^{[12-16]}$ as determined by light scattering (note, however, that the particles of linear polyethylene are not spherical as observerd by TEM and $\mathrm{AFM}^{[32]}$ ). For the case of low-crystalline (and in the example studied also low 


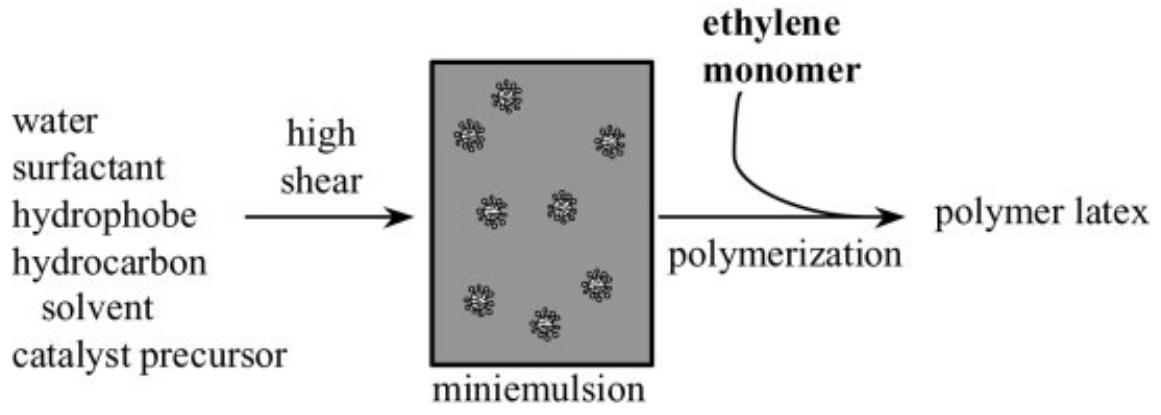

\section{Scheme 1.}

Synthesis of a polyethylene dispersion with a miniemulsion of a catalyst solution. ${ }^{[6]}$

molecular-weight) ethylene-1-olefin copolymers, which have a much higher miscibility with the organic phase present in the miniemulsion droplets (in this case 1-olefin copolymer and some aromatic solvent), Claverie et al. have shown that the number of polymer particles obtained is equal to the number of miniemulsion droplets initially present. ${ }^{[14]}$

\section{Water-soluble Catalysts}

An alternative for the above miniemulsion procedure is the utilization of water-soluble catalyst precursors. In this case, the initial reaction mixture is a single homogeneous aqueous phase, containing surfactant and catalyst.

Polymerization with the in situ-prepared catalyst depicted in Scheme 2 afforded polyethylene dispersions which are transparent or only slightly turbid, depending on the solids content (Figure 1). These dispersions consist of particles of $20 \mathrm{~nm}$ size or less, as evidenced by dynamic light scattering (DLS). ${ }^{[33]}$ Dispersions with solids contents of up to $13 \%$ were obtained without further optimization.

Concerning the particle formation process, chain growth must be expected to start in the aqueous phase by reaction of the water soluble catalyst with ethylene (equilibrium concentration in water at $40 \mathrm{~atm}$ is [ethylene] $]_{\text {water }} \approx 0.1 \mathrm{~mol} \mathrm{~L}^{-1}$ ). Particle formation may occur by homogeneous or heterogeneous nucleation, by analogy to free-radical polymerization. A difference to free-radical emulsion polymerization is obviously that all catalyst precursor is present at the beginning of the reaction by contrast to the continuous formation of radicals. It is at least conceivable that each catalyst precusor molecule generates a particle $^{[33]}$ (or even several particles if exit of catalyst from existing particles occurred). In the overall scheme, this difference to free radical polymerization can account for the observation that unusally small particles are formed. In the aforementioned in situ system, an estimation of the number of nickel centers in the reaction mixture vs. the number of particles formed yields only 20 to 30. Considering the considerable inaccuracy in particle number determination due to errors in average particle size (number $\sim \mathrm{r}^{-3}$ ) and the uncertainty of the portion of nickel atoms which form active sites in the in situ catalyst this can only be an order of magnitude estimation. Thus, it can

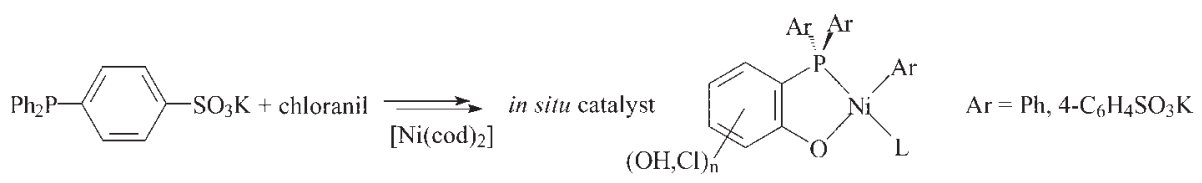

Scheme 2.

In situ synthesis of a water-soluble catalyst. 


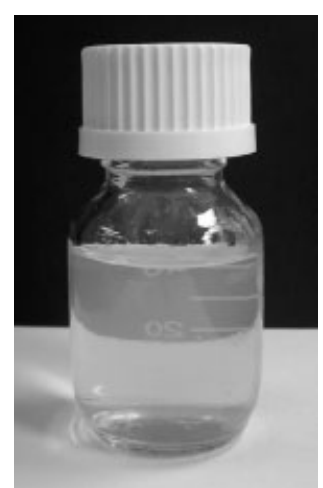

Figure 1.

Polyethylene dispersion prepared with a water-soluble catalyst (polymer solids content 2 wt.-\%). ${ }^{[3]}$

be taken as an indication that indeed the picture of each active metal site forming a particle may apply and that this issue is certainly worth further studies with more defined systems.

A clear advantage of the aforementioned water-soluble catalyst system is that no additional hydrophobic organic solvents are present. This simplifies the system towards the aforementioned miniemulsion procedure, which is advantageous for studies of particle formation mechanisms and also for investigations of the 'nascent' polymer structure.

Another interesting aspect is the accessibility of unusally small polymer particles. There are no general routes for the preparation of polymer particles with sizes $<30 \mathrm{~nm}$. For some polymers, namely polystyrene, polyacrylates or polyacrylamide, free radical polymerization of monomer microemulsions affords polymer particles as small as $10 \mathrm{~nm} .^{[34-39]}$

\section{Catalytic Polymerization in Microemulsions}

While the aforementioned ethylene polymerization with a water-soluble catalyst offers the features outlined in the preceeding section, it requires water-soluble versions of the catalyst precursor (well-defined or formed in situ). However, most catalyst systems known for olefin polymerization are lipophilic.
In general terms, the catalyst miniemulsion procedure as well as the polymerization with a water-soluble catalyst confirm the reasonable assumption that a high initial degree of dispersion of the catalyst is required to form a large number of submicron particles, that is a polymer latex. In order to provide a general route to very small polymer particles enabling the use of known lipophilic catalysts, polymerization with catalyst microemulsions was studied. $^{[40]}$

A microemulsion is a thermodynamically stable mixture of at least two immiscible liquids and a surfactant, which exists in a certain range of compositions. Frequently, an alcohol is added to achieve the microemulsion regime. Microemulsions can possess globular phase structures (oilin-water, o/w or water-in oil, w/o), lamellar or irregular bicontinuous structures. ${ }^{[34]}$ Spontaneous formation, without e.g. strong shearing, and transparency is an indicator for the existence of a microemulsion. Typical dimensions of microemulsions are on the range of a few nanometers, that is microemulsions represent a very high degree of dispersion.

Depending on the physical properties of the monomer (gaseous or liquid under reaction conditions) and the reactivity of the catalyst towards the monomer, different concepts are viable.

In the case of ethylene, which is gaseous under reaction conditions $\left(\mathrm{T}>25^{\circ} \mathrm{C}\right.$; $\mathrm{p}\left(\mathrm{C}_{2} \mathrm{H}_{4}\right)$ up to 40 bar), an aqueous microemulsion of a solution of catalyst in a small amount of toluene was exposed to ethylene in a pressure reactor. This requires the utilization of appropriate portions of the individual components in the system water/ surfactant/toluene/catalyst/optionally alcohol, such that the system is in the microemulsion regime. The surfactant chosen must be compatible with the catalyst in the sense of not interacting with the catalyst such that deactivation results, and it must efficiently stabilize the polymer particles formed. It is also desirable that the system stays in the microemulsion regime in the presence of ethylene, that is a microemul- 
sion is initially present also under polymerization conditions. To this end, typical compositions employed for catalyst microemulsion preparation were observed under ethylene pressure in a pressure reactor equipped with glass windows. The catalyst was omitted, to allow for equilibration without polymer formation. Observation of a transparent homogeneous single phase shows that a particular system indeed is in the microemulsion regime also in the presence of ethylene monomer (Figure 2).

Polymerizing ethylene with such catalyst microemulsions, colloidally stable dispersions consisting of particles as small as $10 \mathrm{~nm}$, as determined DLS, are obtained (Figure 3). ${ }^{[40]}$ Dispersions with substantial polymer solids contents of up to $17 \%$ were prepared. Polymer microstructures and molecular weight vary with the catalyst employed. As also observed in polymerization in miniemulsions, the overall properties of the isolated bulk polymers are similar to polymers prepared with the same catalysts in non-aqueous solution or precipitation polymerization, respectively.

With a catalyst of type 1, linear low molecular weight polyethylene is obtained in microemulsion $\left(\mathrm{M}_{\mathrm{n}} 10^{3}\right.$ to $2 \times 10^{3} \mathrm{~g} \mathrm{~mol}^{-1}$; $\mathrm{M}_{\mathrm{w}} / \mathrm{M}_{\mathrm{n}} 2$ to $\left.4 ; \mathrm{T}_{\mathrm{m}}=120-130^{\circ} \mathrm{C}\right)$. With a catalyst of type $\mathbf{2}$, high molecular weight polyethylene is obtained in the form of very small particles $\left(\mathrm{M}_{\mathrm{n}} 10^{5} \mathrm{~g} \mathrm{~mol}^{-1} ; \mathrm{M}_{\mathrm{w}} / \mathrm{M}_{\mathrm{n}} 2\right.$ to 4). Butadiene can be polymerized 1,2syndiospecifically in aqueous emulsion to afford polymer latices. ${ }^{[41]}$ A $\mathrm{CS}_{2}$-modified Cobalt(I) allyl complex was employed as a catalyst precursor. ${ }^{[42]}$ The latter is prepared in situ by reduction of a $\mathrm{Co}$ (II) salt with $\mathrm{NaBH}_{4}$ in the presence of butadiene. Activation for polymerization occurs upon addition of $\mathrm{CS}_{2}$. This enables the preparation of a microemulsion of butadiene monomer in which the catalyst is dissolved (polymerizations being carried out at a slight pressure given by the vapor pressure of the liquid

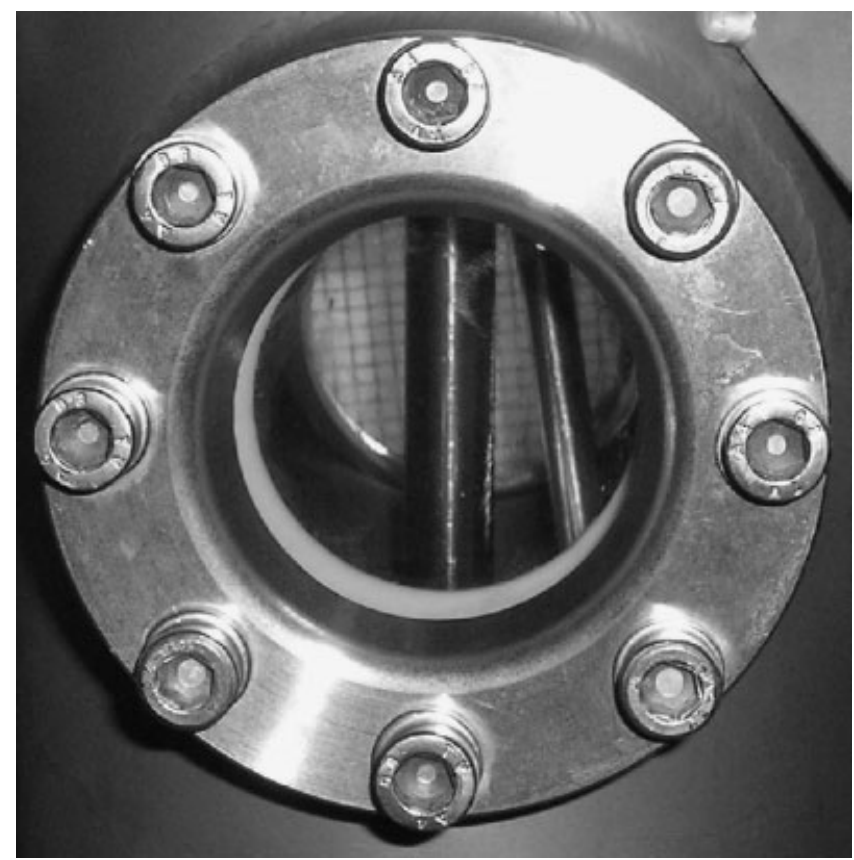

Figure 2.

Optical appearance of a model reaction mixture in the presence of ethylene, confirming presence of a microemulsion (composition: $45.4 \mathrm{~g}$ water; $3.75 \mathrm{~g}$ SDS; $1.88 \mathrm{~g}$ pentanol; $3.00 \mathrm{~g}$ toluene; 20 bar ethylene pressure; $\left.60^{\circ} \mathrm{C}\right)$. 


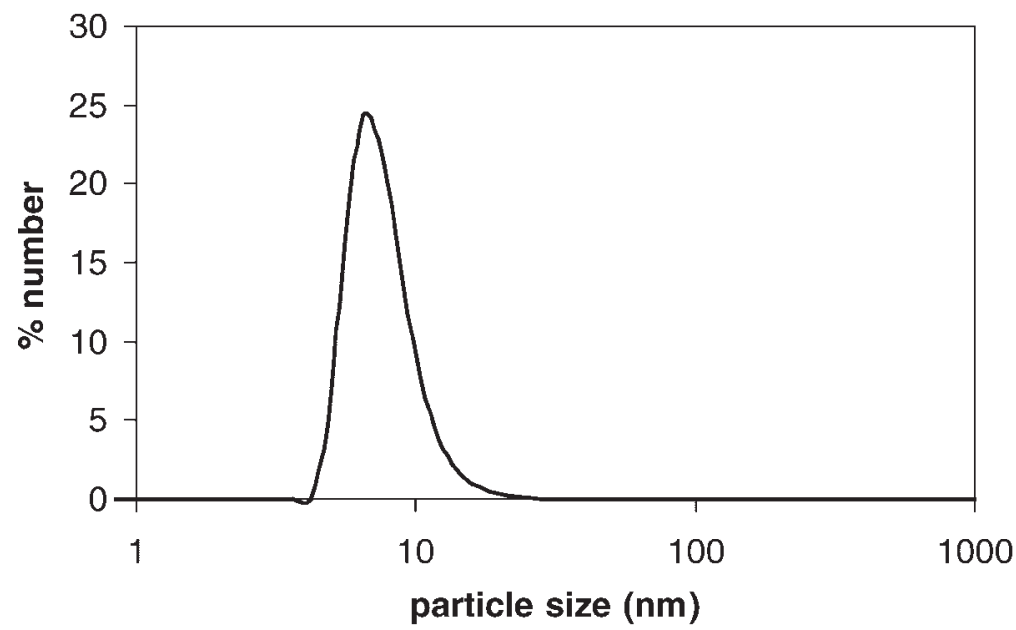

\section{Figure 3 .}

Number-weighted DLS trace of a polyethylene dispersion prepared with a catalyst microemulsion (single angle $173^{\circ}$ backscattering; volume average particle size determined $11 \mathrm{~nm} ; 7.5 \%$ polymer solids content; surfactant: DTAB; $\left.M_{w} 3 \times 10^{3} \mathrm{~g} \mathrm{~mol}^{-1} ; M_{w} / M_{n} 3 \cdot 7\right)$.

monomer). Only upon addition of a small amount of $\mathrm{CS}_{2}$ to this microemulsion polymerization starts. Colloidally stable latices composed of very small particles of stereoregular 1,2-polybutadiene are formed by this procedure (e.g. $14 \mathrm{~nm}$ volume average particle size; polymer properties: $94 \% 1,2$; $6 \% 1,4$-cis, $\mathrm{T}_{\mathrm{m}}=160^{\circ} \mathrm{C}, \mathrm{M}_{\mathrm{w}} 2 \times 10^{5} \mathrm{~g} \mathrm{~mol}^{-1}$, $\left.\mathrm{M}_{\mathrm{w}} / \mathrm{M}_{\mathrm{n}} 2.3\right) .^{[40]}$

In ring opening metathesis polymerization by ruthenium alkylidenes, the high reactivity of the catalyst precursor towards the monomer hampers the aforementioned approach of microemulsifing the catalyst as a solution in the monomer. Combination of seperately prepared microemulsions of the monomer and of the catalyst (in a small amount of toluene) proved to be a suitable approach for this case. Strained (norbornene) and unstrained (cyclooctene and cyclooctene) can be polymerized with Grubbs' $1^{\text {st }}$ and $2^{\text {nd }}$ generation catalyst, respectively, to afford stable latices composed of small particles of 20 to $30 \mathrm{~nm}$ size.

\section{Summary}

Depending on the colloidal state of the initial reaction mixture, unusually small polymer particles with sizes $<30 \mathrm{~nm}$ can be obtained by catalytic polymerization in aqueous systems. Polymers with controlled microstructures, which are inacessible by free-radical polymerization and other polymerization techniques, can be prepared, as demonstrated by the synthesis of dispersions of linear polyethylene, syndiotactic 1,2-polybutadiene or polykalkenamers.

Acknowledgements: Financial support of our studies on catalytic olefin polymerization in aqueous systems by BASF AG, DFG (Me1388/ 3, AM2Net) and BMBF (03X5505) is gratefully acknowledged. S.M. is indebted to the Fonds der Chemischen Industrie and to the HermannSchnell-Foundation. We thank the members of the BASF dispersions division for stimulating discussions.

[1] Emulsion Polymerization and Emulsion Polymers, P. A. Lovell, M. S. El-Aasser, Eds.; Wiley: Chichester, 1997.

[2] Wäßrige Polymerdispersionen, D. Distler, Ed.; VCH: Weinheim, 1999.

[3] S.-Y. Lu, P. Quayle, C. Booth, S. G. Yeates, J. C. Padget Polymer Int. 1993, 32, 1-4.

[4] I. Kühn, B. Mohr, Y. Durant, R. Schwab, R. Leyrer, (BASF) DE 19859191, 2000.

[5] J. P. Claverie, S. Viala, V. Maurel, C. Novat, Macromolecules 2001, 34, 382-8.

[6] A. Held, L. Kolb, M. A. Zuideveld, R. Thomann, S. Mecking, M. Schmid, R. Pietruschka, E. Lindner, M. 
Sunjuk, M. Khanfar, Macromolecules 2002, 35, 33423347.

[7] L. Kolb, R. Thomann, S. Mecking, Macromol. Rapid Commun. 2004, 25, 1824-1828.

[8] S. Mecking, A. Held, F. M. Bauers, Angew. Chem. 2002, 114, 564-582. Angew. Chem Int. Ed. 2002, 41, 544561 (review).

[9] S. Mecking, J. Claverie in Late Transition Metal Polymerization Catalysis (Eds.: B. Rieger, L. S. Baugh, S. Kacker, S. Striegler), Wiley-VCH, Weinheim, 2003 , pp. 231-278.

[10] A. Held, F. M. Bauers, S. Mecking, Chem. Commun. 2000, 301-302.

[11] A. Tomov, J.-P. Broyer, R. Spitz, Macromol. Symp. 2000, 150, 53-58.

[12] F. M. Bauers, S. Mecking, Macromolecules 2001, 34, 1165-1171.

[13] R. Soula, C. Novat, A. Tomov, R. Spitz, J. Claverie, X. Drujon, J. Malinge, T. Saudemont, Macromolecules 2001, 34, 2022-6.

[14] R. Soula, B. Saillard, R. Spitz, J. Claverie, M.F. Llaurro, C. Monnet, Macromolecules 2002, 35, 1513.

[15] F. M. Bauers, M. M. Chowdhry, S. Mecking, Macromolecules 2003, 36, 6711-6715.

[16] F. M. Bauers, S. Mecking, Angew. Chem. 2001, 113, 3112-3115. Angew. Chem Int. Ed. 2001, 40, 30203022.

[17] M. A. Zuideveld, P. Wehrmann, C. Röhr, S. Mecking, Angew. Chem. 2004, 116, 887-891. Angew. Chem Int. Ed. 2004, 43, 869-873.

[18] W. Keim, F. H. Kowaldt, R. Goddard, C. Krueger, Angew. Chem. Int. Ed. Engl. 1978, 17, 466-7;Angew. Chem. 1978, 90, 493.

[19] K. A. Ostoja-Starzewski, J. Witte, Angew. Chem. 1985, 97, 610-2;Angew. Chem. Int. Ed. Engl. 1985, 24, 599-601.

[20] U. Klabunde, S. D. Ittel, J. Mol. Cat. 1987, 41, 12334.

[21] L. K. Johnson, A. M. A. Bennett, S. D. Ittel, L. Wang, A. Parthasarathy, E. Hauptman, R. D. Simpson, J. Feldman, E. B. Coughlin (DuPont) WO98/30609, 1998. [22] T. R. Younkin, E. F. Connor, J. I. Henderson, S. K. Friedrich, R. H. Grubbs, D. A. Bansleben, Science 2000, 287, 460-2.
[23] S. Mecking, Angew. Chem. 2001, 113, 550-557. Angew. Chem Int. Ed. 2001, 40, 534-540 (review).

[24] a) P. Wehrmann, Diploma thesis, Freiburg University, 2003. b) P. Wehrmann, S. Mecking, unpublished results.

[25] A. Held, S. Mecking, Chem. - Eur. J. 2000, 6, 46234629.

[26] D. F. Evans, H. Wennerstroem, The Colloidal Domain: where Physics, Chemistry, Biology, and Technology meet, $2^{\text {nd }}$ Edn., VCH, Weinheim, 1999, p. 66.

[27] K. Landfester, Macromol. Rapid Commun. 2001, 22, 896-936 (review).

[28] E. D. Sudol, M. S. El-Asser in Emulsion Polymerization and Emulsion Polymers, P. A. Lovell, M. S. El-Aasser, Eds.; Wiley: Chichester, 1997, pp. 699-722.

[29] J. M. Asua, Prog. Polym. Sci. 2002, 27, 1283-1346 (review).

[30] A. Chemtob, R. B. Gilbert, Macromolecules 2005 , 38, 6796-6805.

[31] D. Quemener, V. Heroguez, Y. Gnanou, Macromolecules 2005, 38, 7977-7982.

[32] F. M. Bauers, R. Thomann, S. Mecking, J. Am. Chem. Soc. 2003, 125, 8838-8840.

[33] L. Kolb, V. Monteil, R. Thomann, S. Mecking, Angew. Chem. Int. Ed. 2005, 44, 429-432. Angew. Chem. 2005, 117, 433-436.

[34] F. Candeau in Polymerization in Organized Media, Ed.: C. M. Paleos, Gordon and Breach Sci. Publ.: Philadelphia, 1992, pp 215-283.

[35] M. Antonietti, R. Basten, S. Lohmann, Macromol. Chem. Phys. 1995, 196, 441-466.

[36] F. M. Pavel, J. Disp. Sci. Tech. 2004, 25, 1-16.

[37] P. Kuo, N. J. Turro, C. Tseng, M. S. El-Aasser, J. W. Vanderhoff, Macromolecules 1987, 20, 1216-21.

[38] L. Feng, K. Y. S. Ng, Macromolecules 1990, 23, 104853.

[39] K. Min, K. Matyjaszewski, Macromolecules 2005 , 38, 8131-8134.

[40] V. Monteil, P. Wehrmann, S. Mecking, J. Am. Chem. Soc. 2005, 127, 14568-14569.

[41] V. Monteil, A. Bastero, S. Mecking, Macromolecules 2005, 38, 5393-5399

[42] H. Ono, T. Kato, J. Polym. Sci. Part. A : Polym. Chem. 2000, 38, 1083-89. 